\author{
Pedro Álvarez \\ Carmen Alvarado \\ Florence Mathieu \\ Liliana Jiménez \\ Mónica De la Fuente
}

\section{Diet supplementation for 5 weeks with polyphenol-rich cereals improves several functions and the redox state of mouse leucocytes}

Received: 15 November 2005

Accepted: 16 August 2006

Published online: 11 October 2006
P. Álvarez · C. Alvarado · M. De la Fuente Dept. of Animal Physiology

Faculty of Biology

Complutense University of Madrid

Madrid, Spain

M. De la Fuente $(\square)$

Depto. de Fisiología (Fisiología Animal II)

Facultad de Biología

Universidad Complutense

28040 Madrid, España, Spain

Tel.: +34-91/39449-86

Fax: +34-91/39449-35

E-Mail: mondelaf@bio.ucm.es

F. Mathieu · L. Jiménez

Danone Vitapole

Palaiseau, France
Abstract Background Cereals naturally contain a great variety of polyphenols, which exert a wide range of physiological effects both in vitro and in vivo. Many of their protective effects, including an improvement of the function and redox state of immune cells in unhealthy or aged subjects come from their properties as powerful antioxidant compounds. However, whether cereal-based dietary supplementation positively affects the immune function and cellular redox state of healthy subjects remains unclear. Aim of the study To investigate the effects of supplementation (20\% wt/wt) for 5 weeks with four different cereal fractions on healthy mice. Methods Several parameters of function and redox state of peritoneal leukocytes were measured. The cereals, named B (wheat germ), C (buckwheat flour), D (fine rice bran) and $\mathrm{E}$ (wheat middlings) contained different amounts of gallic acid, $p$-hydroxybenzoic acid, vanillic acid, sinapic acid, $p$ coumaric acid, ferulic acid, quercetin, catechin, rutin and oryzanol as major polyphenols. Results In general, all cereal fractions caused an improvement of the leukocyte parameters studied such as chemotaxis capacity, microbicidal activity, lymphoproliferative response to mitogens, interleukin-2 (IL-2) and tumor necrosis factor $(\mathrm{TNF} \alpha)$ release, as well as oxidized glutathione (GSSG), GSSG/GSH ratio, catalase (CAT) activity and lipid oxidative damage. We observed similar effects among the cereal fractions. Conclusions The results suggest that some of these effects may due, at least partially, to the antioxidant activity of the polyphenols naturally present in cereals. Since an appropriate function of the leukocytes has been proposed as marker of the health state, a short-term intake of cereals seems to be sufficient to exert a benefit in the health of the general population. However, further studies are needed to assess the optimal doses and to find out which active polyphenols are able to mediate the observed physiological effects before recommending their regular consumption.

Key words leukocyte functions - leukocyte redox state peritoneal leukocytes polyphenols - health promotion 


\section{Introduction}

Nowadays, consumption of natural products is a matter of major importance as regards health. Indeed, consumption of fruit and vegetables was already associated with a reduced risk of chronic diseases and age-related functional decline several years ago [1]. Nevertheless, less attention has been focused on the importance of phytochemicals from cereals in maintaining health. It is well known that the nutritional status is a central factor contributing to immune system competence [2] and that an adequate function of the immune system is related to health promotion and disease prevention [3]. Nutrients that have traditionally been shown to be required for correct immune system function include different types of vitamins, zinc, copper, and selenium. However, there is an increasing amount of data showing the implication of the so-called "non-nutrients", i.e., phytochemicals, in the immune system responses [4]. Further, the phytochemicals found in natural products have been involved in protecting against a wide range of oxidative stress-related chronic diseases [5]. The overproduction of oxidants and the overwhelming of the antioxidant defence lead to oxidative stress, that can cause oxidative damage to large biomolecules, such as proteins, DNA, and lipids, resulting in an increased risk of disease $[5,6]$. For this reason, to forestall an excessive production of reactive oxygen species (ROS), sufficient amounts of antioxidants need to be consumed. However, the generation of ROS is a key part of normal immune system function [7]. These molecules play a key role in the defence against infectious agents and seem to be involved in regulating many biological processes, serving as second messengers [8]. Thus, it is important to maintain a balance between ROS generation and antioxidant defences within immune cells to ensure a correct functioning of the immune system and help to prevent the onset of chronic diseases.

Cereals naturally contain a wide variety of polyphenols such as the hydroxycinnamic acids, ferulic, vanillic, and $p$-coumaric acids [9], which show a strong antioxidant power and may help to protect from oxidative stress and, therefore, can decrease the risk of contracting many diseases. Flavonoids are present in small quantities, even though their numerous biological effects and their implications for inflammation and chronic diseases have been widely described $[10,11]$. The mechanisms of action of polyphenols go beyond the modulation of oxidative stress-related pathways [6]. Cereal phytochemicals exert their health benefits through multifactorial physiological mechanisms, including enhancement of the immune system and hormones, facilitation of substance transit through the digestive tract, metabolism, modulation and antioxidant, antibacterial and antiviral activities [12].
It is known that unhealthy or aged subjects are more susceptible to infection, showing an impairment of function and redox state of immune cells and that such impairment can be counteracted by antioxidant administration [13, 14]. However, whether dietary antioxidant supplementation affects the functional and redox state of immune cells of healthy subjects remains unclear. Not all subjects are likely to benefit in the same way from supplementation, i.e., there are certain groups within the apparently healthy, general population that benefit from adequate intakes of certain compounds [15].

Since there is an increasing interest in consuming products naturally rich in phytochemicals able to provide health benefits and prevent a wide variety of diseases, in this context we have investigated in the present work the effects of diet supplementation for 5 weeks with different types of cereal fractions naturally rich in polyphenols on certain parameters of immune function and redox state of peritoneal leukocytes from adult healthy mice.

\section{Material and methods}

\section{Animals}

One hundred-fifty female ICR (CD-1) mice (Mus musculus) (Harlan Ibérica, Barcelona, Spain), which were 24 weeks old on arrival to our laboratory, were used. Mice were checked periodically by animal care personnel and were specific pathogen free, as tested by Harlan according to FELASA recommendations, and did not show any sign of malignancy or other pathological processes. The animals were randomly housed in polyurethane boxes, at a constant temperature $\left(22 \pm 2{ }^{\circ} \mathrm{C}\right)$ in sterile conditions inside an aseptic air negative-pressure environmental cabinet (Flufrance, Cachan, France), on a 12/12 h reversed light/ dark cycle. All animals were fed water and standard Sander Mus (A04 diet from Panlab L.S., Barcelona, Spain) pellets ad libitum. The diet was in accordance with the recommendations of the American Institute of Nutrition for laboratory animals. Mice were treated according to the guidelines of the European Community Council Directives 86/6091 EEC. Although we have previously observed that the oestrous cycle phase of mice has no effect on this experimental assay, all females used in the present work were at the beginning of dioestrous.

\section{Experimental groups}

The animals were marked for their individual followup. Five experimental groups, one control $(n=30)$ 
and four supplemented (30 mice per group), were used. The supplementation started at 28 weeks of age. Then, the supplemented groups were fed for a period of 5 weeks, and at the age of $33 \pm 2$ weeks samples were obtained to evaluate certain parameters of function and redox state of peritoneal leukocytes. The experiments were carried out in January at a constant laboratory temperature of $25 \pm 2{ }^{\circ} \mathrm{C}$. Food intake was measured weekly at the same time (9:00-11:00 h). Each animal was fed weekly $50 \mathrm{~g}$ of diet (control or supplemented) and, after 1 week, the uneaten remains were weighed. Body weights were determined once every week. No significant differences on food consumption and body weight among diet groups during the study were observed.

\section{Cereal products and preparation of extracts}

All cereal products (wheat germ, buckwheat flour, fine rice bran and wheat middlings, named $\mathrm{B}, \mathrm{C}, \mathrm{D}$ and $\mathrm{E}$; respectively) used in this study were provided by Danone Vitapole (France). The samples were stored and kept at $-20^{\circ} \mathrm{C}$ prior to analysis. Moisture content of the cereal samples was evaluated by drying at $130^{\circ} \mathrm{C}$ for $90 \mathrm{~min}$. The analyses were done in duplicate. The different extracts were analyzed by Danone Vitapole (France). Briefly, the cereal products were sequentially extracted with water at $50^{\circ} \mathrm{C}$ followed by $80 \%$ methanol and ethyl acetate. Extraction with each solvent was carried out twice for 30 min under $\mathrm{N}_{2}$, in the dark and constant agitation $(200 \mathrm{rpm})$. The ethyl acetate extracts were evaporated under vacuum and re-dissolved in $80 \%$ methanol. The final insoluble pellet was dried. The soluble fractions and the insoluble pellet were stored at $4^{\circ} \mathrm{C}$ (in the dark and under $\mathrm{N}_{2}$ ) prior to analysis of polyphenols and determination of antioxidant activity.

\section{Analysis of total polyphenols and antioxidant activity}

The amount of total phenolic compounds in all extracts was determined by Danone Vitapole (France), according to the Folin-Ciocalteu method [16]. The total phenolic concentration is calculated from a standard curve using a range of concentrations of gallic acid. The results are expressed as milligrams of gallic acid equivalents per gram of material. The antioxidant in vitro activity of the extracts obtained from selected cereal products was evaluated using an Oxygen Radical Absorbance Capacity (ORAC) procedure (Brunswick Laboratories, Wareham, MA, USA). Values are expressed as $\mu \mathrm{mol}$ of Trolox equivalents (TE) per g of dry matter. This assay was conducted in triplicate. There was also a positive correlation between ORAC and total polyphenol content $\left(r^{2}=0.843\right)$.

\section{Preparation of diets}

The control group only received a standard maintenance diet (AO4 diet from Panlab L.S. Barcelona, Spain; see Table 1) and the remaining groups received $80 \%$ of control diet plus $20 \%$ of cereal fractions naturally rich in polyphenols (B, C, D and E; see Table 1). Control and supplemented diets were prepared by mixing the standard maintenance diet or one of the cereal fractions with water, forming a biscuit-shape preparation. Both types of preparations were daily turned upside down and maintained in a dark room for 3 days to obtain a dry preparation. Then, the humidity of the different diets was measured and each of them was stored at $4^{\circ} \mathrm{C}$ for less than 3 weeks, avoiding exposure to light in order to prevent their oxidation.

\section{Collection of peritoneal leukocytes}

Peritoneal suspensions were obtained between 8:00 and $10.00 \mathrm{~h}$, without sacrificing the animals, following the method previously described [17]. Peritoneal leukocytes (macrophages and lymphocytes) were collected, identified, quantified by their morphology using optical microscopy $(40 \times)$ and their concentration was adjusted depending on the function assayed $[14,18]$. The cellular viability, determined in each experiment using the trypan-blue exclusion test, was in all cases higher than $95 \%$.

\section{Leukocyte functions}

The chemotaxis assays were performed according to a technique previously described [14]. The results were expressed as chemotaxis index (C.I.) by counting the number of macrophages and lymphocytes at the lower face of the filters of the Boyden' chambers [14]. The intracellular superoxide anion $\left(\mathrm{O}_{2}^{-}\right)$levels were evaluated as described elsewhere [17]. The results were expressed as nmol of $\mathrm{O}_{2}^{-}$per $10^{6}$ cells. The lymphoproliferation assay and the determination of interleukin-2 (IL-2) levels were carried out following the methods previously described [14]. The proliferation results were expressed as percentage of stimulation by the mitogens Concanavalin A (Con A) or lipopolysaccharide (LPS) with respect to spontaneous proliferation that was considered to be 100 . In the case of IL-2 the results were expressed as $\mathrm{pg} / \mathrm{ml}$. 
Table 1 Nutritional composition of standard (control) and experimental (B, C, D and E) diets

\begin{tabular}{|c|c|c|c|c|c|c|c|c|c|}
\hline \multirow[t]{2}{*}{ Diet ingredients ${ }^{\mathrm{a}}(\mathrm{mg} / 100 \mathrm{~g})$} & \multirow[t]{2}{*}{ Control } & \multicolumn{2}{|l|}{ B } & \multicolumn{2}{|l|}{$C$} & \multicolumn{2}{|l|}{ D } & \multicolumn{2}{|l|}{$E$} \\
\hline & & $\mathrm{HF}$ & $\mathrm{LF}^{\mathrm{b}}$ & $\mathrm{HF}$ & $\mathrm{LF}^{\mathrm{b}}$ & $\mathrm{LF}^{\mathrm{b}}$ & $\mathrm{LF}^{\mathrm{b}}$ & $\mathrm{HF}$ & $\mathrm{LF}^{\mathrm{b}}$ \\
\hline \multicolumn{10}{|l|}{ Polyphenols } \\
\hline Gallic acid & - & - & - & - & 0.49 & - & - & - & - \\
\hline Catechin & - & - & - & 10.8 & 0.19 & 2.04 & 3.34 & - & - \\
\hline$p$-HB acid & - & 0.27 & 0.99 & - & 0.78 & - & - & 1.04 & - \\
\hline Vanillic acid & - & 0.54 & 13.19 & 1.82 & - & 1.93 & - & 0.86 & 0.46 \\
\hline$p$-coumaric acid & - & - & - & 0.21 & 0.16 & 1.28 & 18.91 & 0.06 & 0.68 \\
\hline Sinapic acid & - & - & - & - & 0.45 & 4.73 & - & - & - \\
\hline Ferulic acid & - & 25.97 & 55.60 & 0.42 & 0.09 & 11.75 & 69.19 & 23.83 & 63.06 \\
\hline Quercetin & - & - & $0.17^{\mathrm{a}}$ & - & $2.42^{\mathrm{a}}$ & - & - & - & - \\
\hline Rutin & - & - & $3.94^{\mathrm{a}}$ & - & $11.85^{\mathrm{a}}$ & - & - & - & - \\
\hline Oryzanol & & - & - & - & - & - & $4.03^{\mathrm{a}}$ & - & - \\
\hline \multicolumn{10}{|l|}{ Vitamins } \\
\hline Vitamin A & 0.45 & - & & - & & - & & - & \\
\hline Vitamin D3 & 0.0038 & - & & - & & - & & - & \\
\hline Vitamin E & 2 & 13.65 & & 0.2 & & 1.33 & & 5.55 & \\
\hline Thiamin & 0.1 & 1.87 & & 0.41 & & 1.81 & & 1.48 & \\
\hline Riboflavin & 0.4 & - & & - & & - & & - & \\
\hline Niacin & 2 & - & & - & & - & & - & \\
\hline Pantothenic acid & 1.5 & - & & - & & - & & - & \\
\hline Pyridoxin & 0.4 & 0.87 & & 0.2 & & 0.18 & & 0.68 & \\
\hline Biotin & 0.01 & - & & - & & - & & - & \\
\hline Folacin & 0.1 & 291 & & 45 & & 69 & & 103 & \\
\hline Cobalamine $^{c}$ & 2 & - & & - & & - & & - & \\
\hline Choline & 50 & - & & - & & - & & - & \\
\hline \multicolumn{10}{|l|}{ Fatty acids } \\
\hline Palmitic acid & 460 & - & & - & & - & & - & \\
\hline Palmitoleic acid & 39 & - & & - & & - & & - & \\
\hline Stearic acid & 130 & - & & - & & - & & - & \\
\hline Oleic acid & 650 & - & & - & & - & & - & \\
\hline Linoleic acid & 1,390 & - & & - & & - & & - & \\
\hline Linolenic acid & 130 & - & & - & & - & & - & \\
\hline \multicolumn{10}{|l|}{ Minerals } \\
\hline Calcium & 880 & 25 & & 10 & & 78 & & 62 & \\
\hline Phosphorum & 590 & - & & - & & - & & - & \\
\hline Chloride & 310 & - & & - & & - & & - & \\
\hline Sodium & 250 & - & & - & & - & & - & \\
\hline Potasium & 600 & - & & - & & - & & - & \\
\hline Magnesium & 140 & 259 & & 174 & & 910 & & 203 & \\
\hline Proteins $^{\mathrm{d}}$ & 15.4 & 33.6 & & 11.5 & & 21.3 & & 16.85 & \\
\hline Carbohidrates $^{\mathrm{d}}$ & 101.5 & 21.1 & & 67.4 & & 7.4 & & 28 & \\
\hline Fibre $^{d}$ & 3.9 & 7.7 & & 3.1 & & 40.4 & & 29.3 & \\
\hline
\end{tabular}

Each control (non-supplemented) animal received a 100\% of A04 maintenance diet (Panlab, Barcelona, Spain). Each supplemented animal received an $80 \%$ of A04 maintenance diet plus $20 \%$ of cereal fractions $(B, C, D$ or E) naturally rich in polyphenols. $\mathrm{B}=$ wheat germ; $\mathrm{C}=$ buckwheat flour; $\mathrm{D}=$ fine rice bran; $\mathrm{E}=$ wheat middlings. $\operatorname{ORAC}(\mu$ Trolox Equivalents $/ \mathrm{g}): \quad \mathrm{B}=106 ; \quad \mathrm{C}=81$;

\section{Leukocyte redox state}

Total glutathione and its oxidized form (GSSG) were spectrophotometrically evaluated according to [17]. The results are expressed as $\mathrm{nmol} / 10^{6}$ cells. To calculate the GSSG/GSH ratio, the GSH (reduced form) was obtained by substracting the GSSG values from the total glutathione values. The secretion of mouse tumor necrosis factor alpha (TNF $\alpha)$ was measured in culture supernatants stimulated with LPS, using an ELISA kit (HyCult Biotechnology, Uden, The Neth-
$D=121 ; E=49$. Total polyphenols content (eq $\mathrm{mg}$ gallic acid $/ \mathrm{g}$ ): $B=11.15$; $\mathrm{C}=8.48 ; \mathrm{D}=15.24 ; \mathrm{E}=9.35 . \mathrm{HF}(\mathrm{mg} / 100 \mathrm{~g})=$ hydrosoluble fraction; $\mathrm{LF}(\mathrm{mg} /$ $100 \mathrm{mg})=$ lyposoluble fraction; $p$-HB $=p$-hydroxybenzoic. ${ }^{\mathrm{a}} \mathrm{mg} / 100 \mathrm{~g} .{ }^{\mathrm{b}} \mathrm{mg} /$ $100 \mathrm{mg} .{ }^{c} \mu \mathrm{g} / 100 \mathrm{~g} .{ }^{d} \mathrm{~g} / 100 \mathrm{~g}$

erlands). The results were expressed as $\mathrm{pg} / \mathrm{ml}$, being the minimum detectable value $8 \mathrm{pg} / \mathrm{ml}$. Catalase activity (CAT) was carried out according to [19], slightly modified. Samples of peritoneal suspension (adjusted to $10^{6}$ cells $/ \mathrm{ml}$ ) were resuspended in $50 \mathrm{mM}$ phosphate buffer, sonicated and centrifuged at $3200 \mathrm{~g}$ $\left(4^{\circ} \mathrm{C}\right)$ for $20 \mathrm{~min}$. The reaction was initiated by the addition of $\mathrm{H}_{2} \mathrm{O}_{2}$ and spectrophotometrically measured at $240 \mathrm{~nm}\left(25^{\circ} \mathrm{C}\right)$ for $50 \mathrm{~s}$. The results were expressed as $\mathrm{U} / 10^{6}$ cells. Malondialdehyde (MDA) levels were evaluated according to a technique pre- 

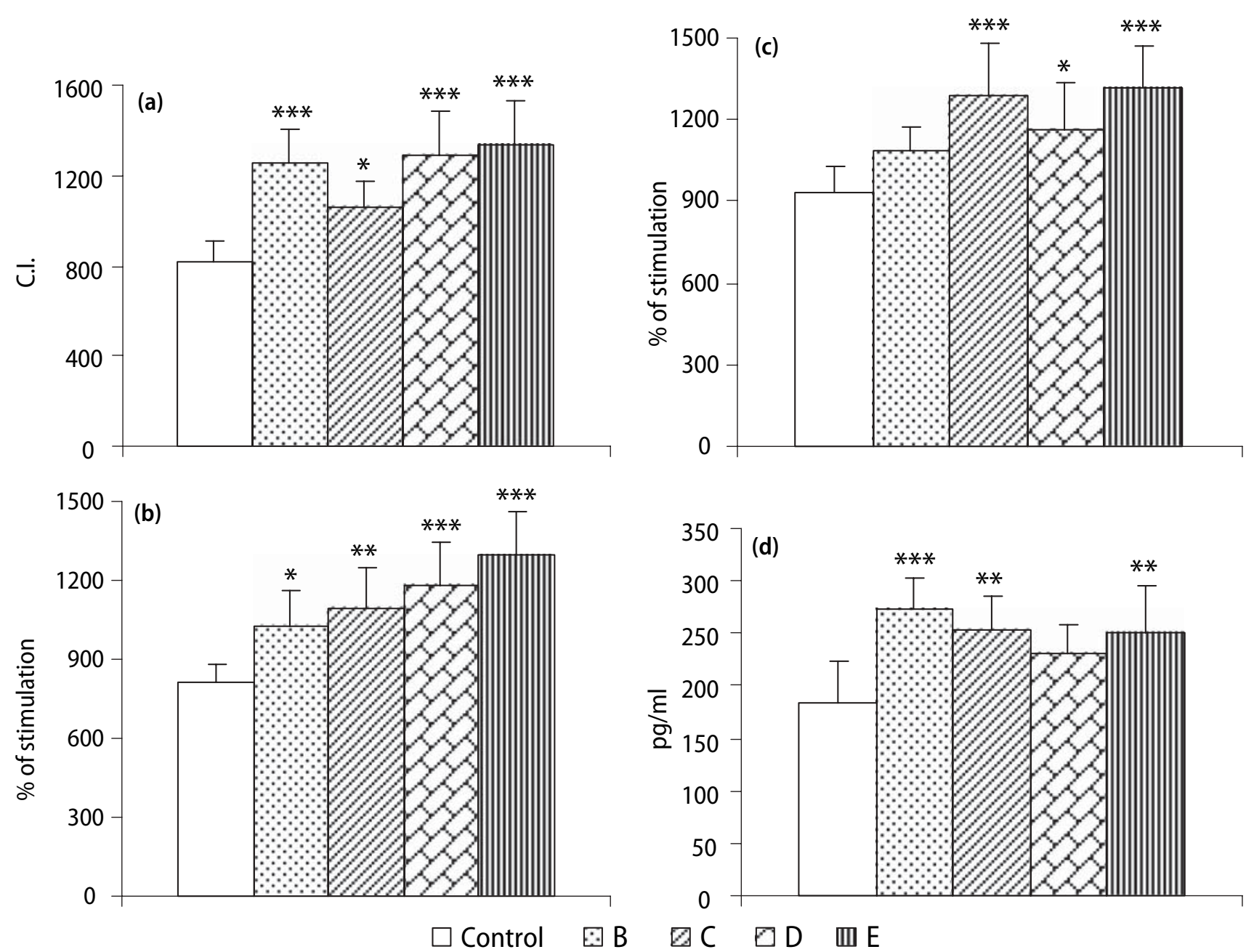

Fig. 1 (a) Chemotaxis capacity of peritoneal lymphocytes, (b) lymphoproliferation in ConA $(1 \mu \mathrm{g} / \mathrm{ml})$-stimulated $48 \mathrm{~h}$-culture supernatants, (c) lymphoproliferation in LPS $(1 \mu \mathrm{g} / \mathrm{ml})$-stimulated $48 \mathrm{~h}$-culture supernatants and (d) release of interleukin-2 (IL-2) in supernatants of $48 \mathrm{~h}$-cultures of peritoneal leukocytes stimulated with Con A $(1 \mu \mathrm{g} / \mathrm{ml})$ from adult female ICR (CD-1) mice supplemented for 5 weeks with cereal fractions (B, C, D or E) naturally rich in polyphenols. Bars show the mean \pm SD of eight values, corresponding to the

viously described [20], slightly modified, and quantified by high performance liquid chromatography (HPLC). Aliquots of peritoneal suspension (adjusted

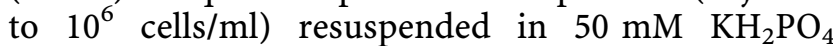
(Sigma) pH 6.8 were sonicated and added to a mixture reaction that contained $0.44 \mathrm{M}$ ortophosphoric acid $\left(\mathrm{H}_{3} \mathrm{PO}_{4}\right.$, Fluka, Steinheim, Germany), 2-thiobarbituric acid $(0.6 \%)$, (TBA, Sigma) and $3 \mathrm{mM}$ butylated hydroxytoluene (BHT, Sigma). It was heated at $95^{\circ} \mathrm{C}$ for $30 \mathrm{~min}$ and after cooling on ice, the samples were extracted adding n-butanol (Panreac), centrifugated at $13,000 \mathrm{rpm}\left(4^{\circ} \mathrm{C}\right)$ for $5 \mathrm{~min}$ and $50 \mu \mathrm{l}$ of supernatants (organic phase) were injected in the HPLC column (Novapack C18, $15 \mathrm{~cm} \times 3.9 \mathrm{~mm}$, Waters). As same number of experiments, being each value the mean of duplicate assays. ${ }^{*} P<0.05{ }^{* *} P<0.01$ and ${ }^{*} * P<0.001$ versus the control group. Lymphoproliferation in response to both mitogens, Con A and LPS, was expressed as \% of stimulation with respect to spontaneous proliferation, the latter considered as 100. Spontaneous lymphoproliferation (in counts per $\mathrm{min}$ ): Control $=1245 \pm 253 ; \quad B=1348 \pm 239 ; \quad C=1071 \pm 171 ; \quad D=1186 \pm 166 ;$ $\mathrm{E}=1052 \pm 169$

mobile phase $50 \mathrm{mM} \mathrm{KH}_{2} \mathrm{PO}_{4} \mathrm{pH} 6.8 /$ methanol (90/10 $\mathrm{v} / \mathrm{v}$ ) was used. The flow rate of the mobile phase was adjusted to $0.4 \mathrm{ml} / \mathrm{min}$. MDA was monitored at $\lambda=532 \mathrm{~nm}$ in a WATERS 486 ultraviolet detector. Standard curves were prepared fresh daily using MDA bis (dimethyl acetal, Sigma). The results were expressed as nmol/ $10^{6}$ cells.

\section{Statistical analysis}

Statistical analysis was performed using the software SPSS 11.5 (Chicago, IL, USA). The data are expressed as the mean \pm standard deviation (S.D.) of the eight 

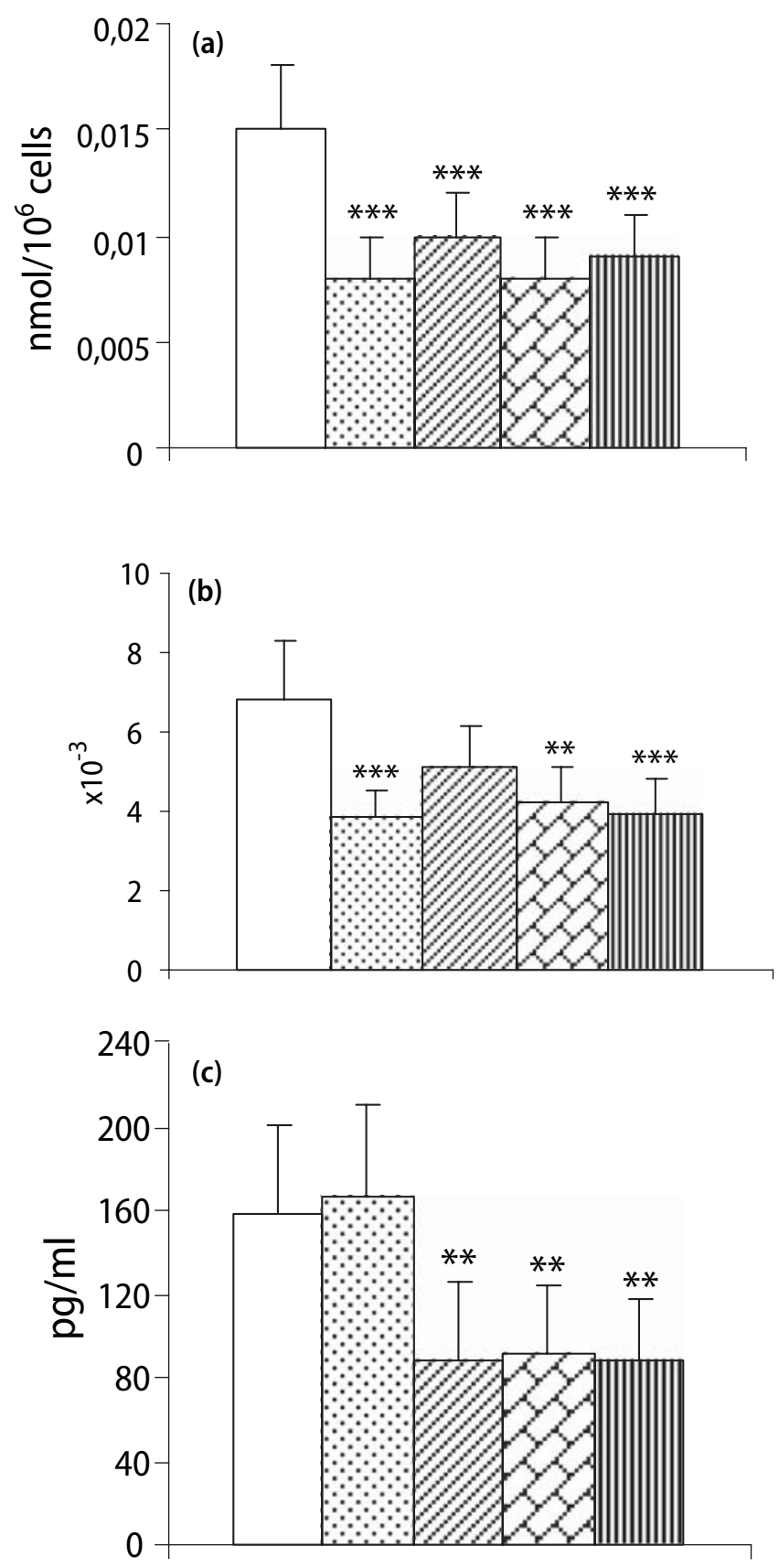

Fig. 2 (a) Oxidized glutathione (GSSG) content, (b) GSSG/GSH ratio, (c) tumor necrosis factor (TNF $\alpha$ ) levels in LPS-stimulated $(1 \mu \mathrm{g} / \mathrm{ml})$ culture supernatants, (d) catalase (CAT) activity and (e) malondialdehyde (MDA) levels in peritoneal leukocytes from adult female ICR (CD-1) mice supplemented for 5 weeks with

values corresponding to the number of experiments. Each value is the mean of the data from assays performed in duplicate. The normality of the samples was confirmed by the Kolmogorov-Smirnov test and the homogeneity of variances by the Levene test. The
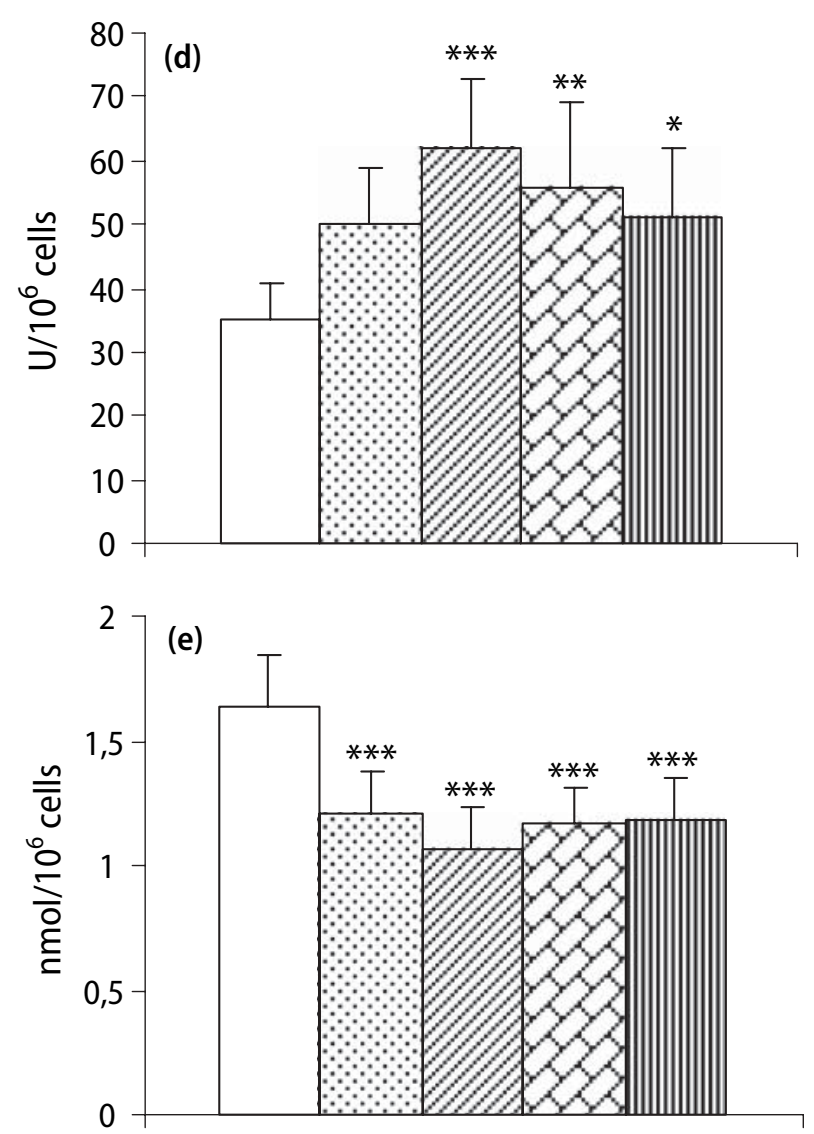

cereal fractions $(B, C, D$ or $E)$ naturally rich in polyphenols. Bars show the mean $\pm S D$ of eight values, corresponding to the same number of experiments, being each value the mean of duplicate assays. ${ }^{*} P<0.05$ ${ }^{* *} P<0.01$ and ${ }^{* *} P<0.001$ versus the control group

data were analysed by the one-way analysis of variance (ANOVA) followed by the Tukey test. The Kruskall Wallis test for non-parametric data was used. The minimum level considered statistically significant was $P<0.05$. 


\section{Results}

\section{Immune system response}

Figure 1 shows the chemotaxis capacity, lymphoproliferative response to the $\mathrm{T}$-cell mitogen Concanavalin A (ConA) or the B-cell mitogen LPS and release of IL2 of peritoneal lymphocytes from adult female mice supplemented for 5 weeks with cereal fractions naturally rich in polyphenols. Mice supplemented with cereals showed a strongly significant increase of lymphocyte chemotaxis compared with that of control mice $(P<0.001$ with $\mathrm{B}, \mathrm{D}$ and $\mathrm{E}$ and $P=0.031$ with C) (Fig. 1a). As regards lymphoproliferative response to Con A (Fig. 1b), mice supplemented with any of the cereals B $(P=0.027), \mathrm{C}(P=0.002), \mathrm{D}(P<0.001)$ or E $(P<0.001)$ showed a significantly higher capacity compared with that of control mice. The supplementation with the cereals $\mathrm{C} \quad(P<0.001)$, D $(P=0.024)$ or $\mathrm{E}(P<0.001)$, but not with $\mathrm{B}$, was able to increase lymphoproliferation in response to LPS with respect to that of non-supplemented mice (Fig. 1c). The secretion of IL-2 by peritoneal leukocytes from mice supplemented with cereal B $(P<0.001), \mathrm{C} \quad(P=0.004)$ or $\mathrm{E}(P=0.006)$ was higher than that of control mice (Fig. 1d). The chemotaxis capacity of macrophages increased significantly in cereal E-supplemented mice in comparison with that of control mice $(434 \pm 39$ versus $290 \pm 42$, $P<0.001)$. The intracellular superoxide anion $\left(\mathrm{O}_{2}^{-}\right)$ levels in non-stimulated peritoneal leukocytes significantly increased after supplementation for 5 weeks with cereal $\mathrm{B}$ and $\mathrm{C}$ with respect to non-supplemented mice (Controls: $24 \pm 5$; B: $42 \pm 7, P<0.001$; C: $41 \pm 7, P<0.001)$. The release of intracellular $\mathrm{O}_{2}^{-}$ from peritoneal leukocytes stimulated with latex beads was significantly higher in mice supplemented with cereals $\mathrm{B}, \mathrm{C}$ and $\mathrm{E}$ (Controls: $52 \pm 5$; $\mathrm{B}$ : $63 \pm 4$, $P=0.045$; C: $67 \pm 8, P=0.002$ E: $64 \pm 7, P=0.021$ ).

\section{Cellular redox state}

The content of oxidized glutathione (GSSG) and the GSSG/GSH ratio, the levels of TNF $\alpha$, CAT activity and MDA levels in peritoneal leukocytes are shown in Fig. 2. All cereal fractions studied decreased significantly the GSSG levels $(P<0.001)$ compared to those of control mice (Fig. 2a). The GSSG/GSH ratio (Fig. 2b) was significantly decreased after supplementation with any of the cereals B $(P<0.001)$, D $(P=0.002)$ or $\mathrm{E}(P<0.001)$ compared with that of non-supplemented mice. Supplementation for 5 weeks with any of the cereals did not cause changes in the GSH levels of peritoneal leukocytes with respect to the values of controls $(2.29 \pm 0.23)$. The secretion of $\mathrm{TNF} \alpha$ decreased in leukocytes from mice supplemented with cereal C $(P=0.005), \mathrm{D}(P=0.007)$ and $\mathrm{E}$ $(P=0.004)$ in comparison with that of non-supplemented mice (Fig. 2c). The CAT activity of peritoneal leukocytes from mice supplemented with cereal $\mathrm{C}$ $(P<0.001), \mathrm{D}(P=0.003)$ and $\mathrm{E}(P=0.040)$ was higher than the activity of this antioxidant enzyme in control mice (Fig. 2d). Finally, the lipid oxidative damage in peritoneal leukocytes, evaluated as MDA levels (Fig. 2e), was lower $(P<0.001)$ in mice supplemented for 5 weeks with cereals than in the control mice.

\section{Discussion}

It is widely accepted that antioxidant compounds may help to protect against oxidative stress, with resulting health promotion and disease prevention [21]. Moreover, an adequate intake of these compounds can enhance certain aspects of immune function, which is related to health [4]. Thus, it is becoming clear that diet supplementation with appropriate amounts of antioxidants enhances the immune function and improves the redox state of unhealthy subjects [15]. However, whether antioxidant supplementation has these effects in healthy subjects, still remains unknown. In the present study the cereal fractions used were able to improve several aspects of immune function. Thus, important events of innate immune response, i.e., migration capacity (chemotaxis) and microbicidal activity (intracellular superoxide anion levels), appear to be effectively affected by the supplementation with cereals naturally rich in polyphenols. Akbay et al. [22] showed that the three flavonoid glycosides from Urtica dioica L., quercetin-3-O-rutinoside, kaempherol-3-O-rutinoside and isorhamnetin-3-O-glucoside increased, in vitro, the chemotaxis and the intracellular killing activity of neutrophils, using methods similar to those of the present work. In our study, the fraction E is only able to enhance macrophage chemotaxis, whereas all the cereal fractions were able to show a strong stimulatory effect on this function in lymphocytes. This fact suggests that the polyphenols present in cereal fractions could exert a cell-dependent effect on migration capacity. Since a higher NF- $\kappa \mathrm{B}$ expression is linked to an increased production of migratory inhibitory factor (MIF), thus being responsible for a decreased migration capacity [13], and several polyphenols are able to inhibit NF- $\kappa \mathrm{B}$ activation [23], it seems plausible that some of the polyphenols present in the cereals used in our study could enhance the chemotaxis capacity through their action on NF- $\kappa \mathrm{B}$ activation. All cereal fractions used in the present work, with the exception of $D$, have been shown to increase 
the microbicidal activity of peritoneal leukocytes. Since $p$-hydroxybenzoic acid is not present in fraction $\mathrm{D}$, this compound could be responsible for that effect. However, to date, there is no evidence of a microbicidal activity increase following $p$-hydroxybenzoic acid administration.

Lymphoproliferation is a crucial event of the acquired immune response. Several studies have demonstrated a strong stimulatory effect on this capacity and on the cytokine well-known as enhancer of proliferative response, namely the IL-2, after antioxidant supplementation. Thus, Bub et al. [4] showed an increase in both functions in peripheral blood mononuclear cells (PBMC) from healthy subjects after diet supplementation with fruit juices rich in polyphenolic compounds. In ethanol-fed mice, Cheshier et al. [24] demonstrated an increased IL-2 production by mitogen-stimulated splenocytes after in vitro administration of Pycnogenol ${ }^{\circledR}$, a commercial combination of phenolic compounds from pine bark. To date, no studies on the effect of the isolated polyphenolic compounds of the cereals used in the present research on these functions have been carried out.

Glutathione (GSH) plays important roles in antioxidant defence, nutrient metabolism and regulation of many cellular events, and its deficiency contributes to the oxidative stress-related pathogenesis of several chronic diseases [25]. Both the oxidized glutathione (GSSG) content and the GSSG/GSH ratio, the latter being considered a sensitive marker of cellular oxidative stress [26], were significantly decreased after supplementation with all the cereal fractions, although fraction $\mathrm{C}$ only showed a tendency to diminish the GSSG/GSH ratio. However, the GSH content of peritoneal leukocytes was not changed after cerealbased supplementation, suggesting that the lower GSSG/GSH ratio observed is primarily due to diminutions of the GSSG content. Rosenblat et al. [27] demonstrated that isoflavonoid glabridin $(25 \mu \mathrm{g} / \mathrm{kg} /$ day) supplementation was able to reduce the GSSG content in murine peritoneal macrophages. However, the same authors also observed increased GSH levels in these immune cells.

Tumor necrosis factor is one of the most common proinflammatory cytokines produced predominantly by macrophages that has been reported to increase in many oxidative stress-related chronic diseases [28]. Our study showed that each of the cereal fractions, except $\mathrm{B}$, was able to decrease the secretion of TNF $\alpha$ by peritoneal leukocytes. In agreement with Wang and Mazza [29], catechin at a concentration of $31 \mu \mathrm{M}$ inhibited the TNF $\alpha$ production of LPS/IFN $\gamma$-activated RAW 264.7 macrophages. However, our results suggest that $p$-coumaric acid could also have an important anti-inflammatory role because this common phenolic acid is present in each cereal fraction, except the B. Moreover, in rats with endotoxemia, two different doses $(75,150 \mathrm{mg} / \mathrm{kg}$, i.p.) of a water extract of propolis, a natural product rich in $p$-coumaric acid, were able to inhibit $\mathrm{TNF} \alpha$ production in plasma [30]. Nevertheless, other authors did not observe any effect on $\mathrm{TNF} \alpha$ production in whole blood cultures in the presence of phenolic compounds like $p$-coumaric acid at the concentrations of $10^{-7}-10^{-4} \mathrm{M}$ [31]. The most probable mechanism triggered by phenolic compounds for blocking LPS-induced production of TNF $\alpha$ by macrophages could be the inhibition of NF-kB activation [23].

Catalase plays a fundamental role in protecting cells against oxidative damage [32]. Decreased CAT activity may compromise the overall enzymatic defence system. In the present study, each of the cereal fractions increased CAT activity in peritoneal leukocytes, although fraction B only showed a tendency to increase this enzymatic activity. In other study, the renal CAT activity was significantly increased in rats fed black rice, one of the most important cereals rich in phenolic acids [33]. Khan et al. [34] showed that following oral feeding $(0.2 \% \mathrm{w} / \mathrm{v})$ for 30 days of polyphenols from green tea, a popular beverage rich in catechin, CAT activity significantly increased in the small bowel, liver and lungs of mice. In fact, fractions $\mathrm{C}$ and $\mathrm{D}$ (the fractions rich in catechin) showed the greatest effect. The present data suggest that $p$ coumaric acid, which is present in almost all the cereal fractions ( $\mathrm{C}, \mathrm{D}$ and $\mathrm{E}$ ) might also have a relatively important role in modulating the CAT activity. Indeed, an oral administration of $p$-coumaric acid $(100 \mathrm{mg} / \mathrm{kg})$ for five days ameliorated the CAT activity in the heart from rats treated with doxorubicin, an anticancer antibiotic [35]. This potential protective action of $p$-coumaric acid is likely to be due to its free radical scavenging power.

ROS generation is able to promote oxidative damage to fatty acids present in biological membranes via an autocatalytic process known as lipid peroxidation. Malondialdehyde is one of the endproducts of this process [36], which is related to the onset of chronic diseases [37]. In the present work, all the cereal fractions strongly decreased the MDA levels in peritoneal leukocytes. It has been observed that highly reactive and destructive hydroxyl radicals are effectively scavenged by oral administration of $p$ coumaric acid ( $317 \mathrm{mg} /$ day) for 30 days in rats [38], which might decrease the potential damage to biological membranes by lowering MDA production. Several authors have shown that rutin, quercetin or catechin, which are some of the flavonoids present in the cereals used in the present work, are able to decrease lipid oxidative damage $[39,40]$. The same happens with ferulic acid, the most common phe- 
nolic acid in cereal cell walls, which inhibit peroxidation [41]. Red wine polyphenols, together with ascorbic acid, inhibit lipid peroxidation in human muscle tissue [42]. The same authors demonstrated that, in the presence of catechin, ascorbic acid at $\mathrm{pH}$ 3.0 works in a sinergystic way preventing lipid oxidative damage and $\beta$-carotene cooxidation. This fact might explain the central role that consuming natural products rich in polyphenolic antioxidants, like cereals, has in promoting health and preventing the onset of chronic diseases.

The present data demonstrate the importance of polyphenol-rich cereal consumption because not only has shown to be very effective for modulating several parameters of immune function, but also is able to improve to a large extent the redox state of immune cells from mice. More importantly, we have demonstrated that cereal-based antioxidant supplementation can exert beneficial effects in healthy mice and thus we suggest that normal healthy populations may benefit from this supplementation. Indeed, a recent study has provided evidence for potential protective effects of moderate consumption of polyphenol-rich red wine in healthy subjects [43]. It has been reported that subjects susceptible to infections or suffering from chronic inflammatory processes showing an impairment of function and redox state of immune cells likely to benefit from antioxidant administration [13, 14]. However, it is difficult to know whether there is changes or not in the healthy mice from the present study may be a reliable predictor for the nutrient-immune requirements in disease-associated, unhealthy mice. To confirm this possibility we should know the optimal combination and quantities of nutrients, the potential interactions that might occur between these nutrients and the most appropiate time at which that immunonutrition should be provided. In words of Berger [15], "the efficiency of supplementation is a question of timing. Antioxidant nutrients cannot cure an installed disease, but they may prevent its promotion".

It is important to point out that the cereal fractions used by us contain other compounds, both nutrients and non-nutrients, such as vitamins, minerals or fibre and, therefore, we cannot rule out that they can result in health benefits. However, the present cereal fractions show a good correlation coefficient between total antioxidant capacity and content of phenolic compounds, thus suggesting that polyphenols are largely responsible for the antioxidant activity of the different cereal fractions, which ultimately may help to protect from oxidative stress and, consequently, can decrease the risk of many potential diseases. Nevertheless, it is important to take into account some issues. First, the doses used play a crucial role, since it is known that excessive amounts of antioxidant compounds can impair the immune function [44] or even becomes potentially prooxidants [45]. Yet, we have not used "megadoses", but nutritional doses of polyphenols. Second, the present recommendation is not a single polyphenol-based supplementation to modulate the antioxidant status or the immune system, but it is the combination of different substances as the best way to provide protective action $[46,47]$. Therefore, the cereals used by us contain a complex natural mixture of polyphenols of different size, polarity and solubility. Third, we can speculate that one of the reasons for the protective effects of cereals could be that the metabolism of polyphenols carried out by the gut microflora [48] is able to provide immune protection beyond the gut. Fourth, it should not be ruled out the possibility that synergistic and/or additive effects occur. Several studies have shown that polyphenols can work synergistically with other antioxidant compounds [42, 49]. Thus, it is of great physiological importance that many polyphenols of different solubility will interact in the body cells and compartments, with antioxidants recharging adjacent antioxidants in an integrated manner [50]. Finally, we consider the present nutritional intervention in animals as preventive, but not therapeutic, since it is able to maintain the normal functional and redox status of the body cells from a general population of mice. Therefore, we do not deliver a cereal-based antioxidant supplement to unhealthy subjects, i.e., in conditions caused by excessive free radicals generation. In conclusion, we strongly believe that polyphenols naturally present in cereals may have important implications for health preservation, by acting, al least partly, as modulators of immune function and redox state. Although we emphasize the importance of further studies on this subject, we suggest the use of this type of supplementation for the general population since "prevention is a much more effective approach that treatment of disease".

\footnotetext{
Acknowledgments This work was supported by a grant from Danone Vitapole S.A. We thank Armelle Schlumberger and Chantal Lamich from Danone Vitapole respectively for the helpful comments on this topic and the phenolic compounds analysis.
} 


\section{References}

1. Keli SO, Hertog MG, Feskens EJ, Kromhout D (1996) Dietary flavonoids, antioxidant vitamins, and incidence of stroke: the Zutphen study. Arch Interm Med 156:637-642

2. Chandra RK (2004) Impact of nutritional status and nutrient supplements on immune responses and incidence of infection in older individuals. Ageing Res Rev 3:91-104

3. Dean K (1997) Creating knowledge relevant for public health applications in immunology and aging. Mech Ageing Dev 94:251-262

4. Bub A, Watzl B, Blockhaus M, Briviba K, Liegibel U, Müller H, Pool-Zobel BL, Rechkemmer G (2003) Fruit juice consumption modulates antioxidant status, immune status and DNA damage. J Nutr Biochem 14:90-98

5. Ames BN, Gold LS (1991) Endogenous mutagens and the causes of aging and cancer. Mut Res 250:3-16

6. Scalbert A, Johnson IT, Saltmarsh M (2005) Polyphenols: antioxidants and beyond. Am J Clin Nutr 81:215S-217S

7. Knight JA (2000) Review: free radicals, antioxidants, and the immune system. Ann Clin Lab Sci 30:145-157

8. Finkel T (2003) Oxidant signals and oxidative stress. Curr Opin Biol 15:247254

9. Baublis AJ, Lu C, Clydesdale FM, Decker EA (2000) Potential of wheatbased breakfast cereals as a source of dietary antioxidants. J Am Coll Nutr 19:308-311

10. Middleton EJ, Kandaswami C, Theoharides TC (2000) The effects of plant flavonoids on mammalian cells: implications for inflammation, heart disease, and cancer. Pharmacol Rev 52:673-751

11. Havsteen BH (2002) The biochemistry and medical significance of the flavonoids. Pharmacol Ther 96:67-202

12. Lupton JR, Maccher MM (1988) Radiographic analysis of the effect of dietary fibers on rat colonic transit time. Am J Physiol 255:633-639

13. Víctor VM, Rocha M, De la Fuente $M$ (2004) Immune cells: free radicals and antioxidants in sepsis. Int Immunopharmacol 4:327-347

14. Alvarado C, Álvarez P, Jiménez L, De la Fuente M (2005) Improvement of leukocyte functions in young prematurely aging mice after a 5-week ingestion of a diet supplemented with biscuits enriched in antioxidants. Antiox Redox Signal 7:1203-1210

15. Berger MM (2005) Can oxidative damage be treated nutritionally? Clin Nutr 24:172-183
16. Singleton VL, Rossi JA (1965) Colorimetry of total phenolics with phosphomolybdic-phosphotungstic reagents. Am J Enol Vitic 16:144-158

17. De la Fuente M, Hernanz A, Guayerbas $\mathrm{N}$, Álvarez P, Alvarado C (2004) Changes with age in peritoneal macrophage functions. Implication of leukocytes in the oxidative stress of senescence. Cell Mol Biol 50:OL683OL690

18. Puerto M, Guayerbas N, Víctor VM, De la Fuente M (2002) Effects of $N$-acetylcysteine on macrophage and lymphocyte functions in a mouse model of premature aging. Pharmacol Biochem Behav 73:797-804

19. Beers RF, Sizer IW (1952) A spectrophotometric method for measuring the breakdown of hydrogen peroxide by catalase. J Biol Chem 195:133-140

20. Chirico S, Smith C, Marchant C, Mithison MJ, Halliwell B (1993) Lipid peroxidation in hyperlipemic patients. A study of plasma using an HPLC-based thiobarbituric acid test. Free Radic Res 19:51-57

21. Liu RH (2003) Health benefits of fruits and vegetables are from additive and synergistic combinations of phytochemicals. Am J Clin Nutr 78:517S$520 \mathrm{~S}$

22. Akbay P, Basaran AA, Undeger U, Basaran N (2003) In vitro immunomodulatory activity of flavonoid glycosides from Urtica dioica L. Phytother Res 17:34-37

23. Ma Q, Kinneer K, Ye J, Chen BJ (2003) Inhibition of nuclear factor kappaB by phenolic antioxidants: interplay between antioxidant signaling and inflammatory cytokine expression. Mol Pharmacol 64:211-219

24. Cheshier JE, Ardestani-Kaboudanian S, Liang B, Araghiniknam M, Chung S, Lane L, Castro A, Watson RR (1996) Immunomodulation by pycnogenol in retrovirus-infected or ethanol-fed mice. Life Sci 58:87-96

25. Wu G, Fang YZ, Yang S, Lupton JR, Turner ND (2004) Glutathione metabolism and its implication for health. J Nutr 134:489-492

26. Dröge W (2002) Free radicals in the physiological control of cell function. Physiol Rev 82:47-95

27. Rosenblat $M$, Coleman $R$, Aviram $M$ (2002) Increased macrophage glutathione content reduces cell-mediated oxidation of LDL and atherosclerosis in apolipoprotein E-deficient mice. Atherosclerosis 163:17-28

28. Krabbe KS, Pedersen M, Bruunsgaard $\mathrm{H}$ (2004) Inflammatory mediators in the elderly. Exp Gerontol 39:687-699
29. Wang J, Mazza G (2002) Effects of anthocyanins and other phenolic compounds on the production of tumor necrosis factor alpha in LPS/IFN-gamma-activated RAW 264.7 macrophages. J Agric Food Chem 50:4183-4189

30. http//:www.naturalclinic.net/new3

31. Miles EA, Zoubouli P, Calder PC (2005) Differential anti-inflammatory effects of phenolic compounds from extra virgin olive oil identified in human whole blood cultures. Nutrition 21:389394

32. Sun Y (1990) Free radicals, antioxidant enzymes and carcinogenesis. Free Radic Biol Med 8:585-599

33. Toyokuni S, Itani $\mathrm{T}$, Morimitsu $\mathrm{Y}$, Okada K, Ozeki M, Kondo S, Uchida K, Osawa T, Hiai H, Tashiro T (2002) Protective effect of colored rice over white rice on Fenton reaction-based renal lipid peroxidation in rats. Free Radic Res 36:583-592

34. Khan SG, Katiyar SK, Agarwal R, Mukhtar H (1992) Enhancement of antioxidant and phase II enzymes by oral feeding of green tea polyphenols in drinking water to $\mathrm{SKH}-1$ hairless mice: possible role in cancer chemoprevention. Cancer Res 52:4050-4052

35. Abdel-Wahab MH, El-Mahdy MA, Abd-Ellah MF, Helal GK, Khalifa F, Hamada FM (2003) Influence of $p$ coumaric acid on doxorubicin-induced oxidative stress in rat's heart. Pharmacol Res 48:461-465

36. Kurata M, Suzuki M, Agar NS (1993) Antioxidant systems and erythrocyte life-span in mammals. Comp Biochem Physiol 106:477-487

37. Tug T, Karatas F, Terzi SM (2004) Antioxidant vitamins (A, C and E) and malondialdehyde levels in acute exacerbation and stable periods of patients with chronic obstructive pulmonary disease. Clin Invest Med 27:13-128

38. Zang LY, Cosma G, Gardner H, Shi X, Castranova V, Vallyathan V (2000) Effect of antioxidant protection by $p$ coumaric acid on low-density lipoprotein cholesterol oxidation. Am J Physiol Cell Physiol 279:954-960

39. Tero J, Piskula MK (1998) Flavonoids as inhibitors of lipid peroxidation in membranes. In: Rice-Evans CA, Packer $\mathrm{L}$ (eds) Flavonoids in health and disease. Marcel Dekker, Inc, New York, pp 277-293

40. Afanas'eva IB, Ostrakhovitch EA, Mikhal'chik EV, Ibragimova GA, Korkina LG (2001) Enhancement of antioxidant and anti-inflammatory activities of bioflavonoid rutin by complexation with transition metals. Biochem Pharmacol 61:677-684 
41. Uchida $M$, Nakajin S, Toyoshima $S$, Shinoda M (1996) Antioxidative effect of sesamol and related compounds on lipid peroxididation. Biol Pharm Bull 19:623-626

42. Gorelik S, Lapidot T, Shaham I, Granit R, Ligumsky M, Kohen R, Kanner J (2005) Lipid peroxidation and human gastric fluid inhibited by dietary polyphenols: health implications. J Agric Food Chem 53:3397-3402

43. Tsang C, Higgins S, Duthie GG, Duthie SJ, Howie M, Mullen W, Lean ME, Crozier A (2005) The influence of moderate red wine consumption on antioxidant status and indices of oxidative stress associated with CHD in healthy volunteers. Br J Nutr 93:233240
44. Calder PC, Kew S (2002) The immune system: a target for functional foods? $\mathrm{Br}$ J Nutr 88:S165-S177

45. Sakihama Y, Cohen MF, Grace SC, Yamasaki H (2002) Plant phenolic antioxidant and prooxidant activities: phenolics-induced oxidative damage mediated by metals in plants. Toxicology $177: 67-80$

46. Moskaug JO, Carlsen H, Myhrstad MC, Blomhoff R (2005) Polyphenols and glutathione synthesis regulation. Am J Clin Nutr 81:277S-283S

47. Sierra S, Lara-Villoslada F, Olivares M, Jiménez J, Boza J, Xaus J (2005) Increased immune response in mice consuming rice bran oil. Eur J Nutr 44:509-516
48. Manach C, Scalbert A, Morand C, Rémésy C, Jiménez L (2004) Polyphenols: food sources and bioavailability. Am J Clin Nutr 79:727-747

49. Lu C, Liu Y (2002) Interactions of lipoic acid radical cations with vitamins $\mathrm{C}$ and $\mathrm{E}$ analogue and hydroxycinnamic derivatives. Arch Biochem Biophys 406:78-84

50. Eastwood MA (1999) Interaction of dietary antioxidants in vivo: how fruit and vegetables prevent diseases? Q J Med 92:527-530 